\title{
Some features of calculation of the reinforced concrete bent elements and economic assessment of design
}

\author{
Asmik Klochko ${ }^{1 *}$, Aleksej Klochko ${ }^{2}$ \\ ${ }^{1}$ Moscow state university of civil engineering, Yaroslavskoye shosse, 26, Moscow, Russia, 129337 \\ ${ }^{2}$ Moscow state university of civil engineering, Yaroslavskoye shosse, 26, Moscow, Russia, 129337
}

\begin{abstract}
At the design stage of the reinforced concrete bent elements, and also at their strengthening by method of accumulation of section, it is necessary to aspire to that the settlement strain-stress distribution of an element corresponded to actual. Importance of this circumstance is that their discrepancy can lead to increase in both economic, and not economic risks at exploitation of construction. In this article some features of calculation which are directly influencing profitability during creation new or strengthening of the rod-shaped bending structure are considered.
\end{abstract}

\section{About the provision of the neutral axis of section of the bent element}

According to the provisions formulated in [1], the bending moment perceived by the bending element of rectangular section $\mathrm{M}_{\mathrm{ult}}$, at observance of a condition:

$$
\xi=\frac{x}{h_{0}} \leq \xi_{R}
$$

is defined by a formula:

$$
M_{u l t}=R_{b} \cdot b \cdot x \cdot\left(h_{0}-0.5 x\right)+R_{s c} \cdot A_{s}^{\prime} \cdot\left(h_{0}-a^{\prime}\right),
$$

where height of the compressed zone $(\mathrm{h})$ is defined from a balance condition:

$$
R_{b} \cdot b \cdot x+R_{s c} \cdot A_{s}^{\prime}=R_{s} \cdot A_{s}
$$

It is important that in the equation (3) the area of compression reinforcement $A_{s}^{\prime}$ fulfill conditions:

\footnotetext{
*Corresponding author: asmik1985@mail.ru
} 


$$
A_{S}^{\prime}<\frac{R_{S}}{R_{S c}} \cdot A_{s}
$$

Otherwise, if:

$$
A_{S}^{\prime} \geq \frac{R_{S}}{R_{S c}} \cdot A_{S}
$$

that height of the compressed zone $-\mathrm{x}$, calculated from the equation (3), will turn out zero or negative which physical sense can't be understood. It cannot be assumed that the compression pressure in fittings can reach the extreme $R_{s c}$, value if it is in concrete in which tension steadily remains zero. It is obvious that at the overestimated values of the area of the compressed fittings (5) the settlement strain-stress distribution of a design described by a formula (3) doesn't correspond to actual state and therefore, it will be correct to present it in the form:

$$
\sigma_{b} \cdot b \cdot x+\sigma_{s c} \cdot A_{s}^{\prime}=R_{s} \cdot A_{s}
$$

meaning that at the moment when tension in the stretched fittings reaches the limit state, tension in materials of the compressed zone doesn't manage to reach extreme values, and height of the compressed zone $(\mathrm{x})$ surely covers the compressed fittings:

$$
\sigma_{b}<R_{b} ; \quad \sigma_{s c}<R_{s c} ; \quad x>\mathrm{a}^{\prime}
$$

where $a^{\prime}$ - distance from the compressed element side to the center of gravity of the compressed fittings.

This circumstance isn't threat for reliable operation of a construction. It testifies only to excessive margin of safety of materials of the compressed zone and, so, to inefficient designing. Therefore, from the economic point of view, it is expedient that the area of the compressed fittings has been chosen within (4).

However researches show that similar (7) is observed as well at some values from a condition (4) at which the neutral axis of section gets to an interval $0 \div \mathrm{a}^{\prime}$.

We will show it on the example of 1.

Example 1.

It is required to define the limit bending $M_{\text {ult }}$ moment for a beam with $b=40$ sm section sizes; $\mathrm{h}=45 \mathrm{sm}$; made of class $\mathrm{B} 20$ concrete. The stretched fittings are accepted by $\mathrm{A}_{\mathrm{s}}=15.2$ cm2 (4Ø22 A400 s). For the compressed fittings we will consider two options:

option-1: $\mathrm{A}_{\mathrm{s}}^{\prime}=12.32 \mathrm{~cm} 2(2 \varnothing 28 \mathrm{~A} 400 \mathrm{~s})$

option-2: $\mathrm{A}_{\mathrm{s}}^{\prime}=5.09 \mathrm{~cm} 2(2 \varnothing 18 \mathrm{~A} 400 \mathrm{~s})$.

Accounting results are given in table 1.

Table 1. Accounting results

\begin{tabular}{|c|c|c|c|c|c|c|c|}
\hline \multirow{2}{*}{ Example 1 } & $\mathrm{x}$ & $\xi$ & $\xi_{\mathrm{R}}$ & $\mathrm{A}_{\mathrm{s}}^{\prime}$ & $\mathrm{A}_{\mathrm{s}}$ & $\begin{array}{c}\text { Expense } \\
\text { fittings }\end{array}$ & $\mathrm{M}_{\mathrm{ult}}$ \\
\cline { 2 - 7 } & $\mathrm{cm}$ & & & $\mathrm{cm} \mathrm{2}$ & $\mathrm{cm} \mathrm{2}$ & $\mathrm{kg} / \mathrm{m} 3$ & $\mathrm{kNm}$ \\
\hline Option-1 & 2.2 & 0.056 & 0.589 & 12.32 & 15.2 & 120.0 & 198.3 \\
\hline Option-2 & 7.9 & 0.197 & 0.589 & 5.09 & 15.2 & 88.5 & 198.1 \\
\hline
\end{tabular}


We will notice that in both options the condition (1) is satisfied. However in the first option the compressed zone of section doesn't cover the compressed fittings: $x=2.2 \mathrm{sm}<a^{\prime}=5.0 \mathrm{sm}$. It means that the condition of balance of section is more precisely described by the equation (6), but not the equation (3) because the compressed fittings can't be out of a zone of the compressed concrete. So the case described in (7) when in a limit condition of a design of tension in materials of the compressed zone don't reach the extreme values takes place. The fact that such designing isn't economic becomes obvious of comparison of settlement these both options.

So, in the second option the compressed section zone covers the compressed fittings now: $\mathrm{x}=7.9 \mathrm{~cm}<\mathrm{a}^{\prime}=5.0 \mathrm{~cm}$. In other words in a extreme limit state of an element the tension in materials of the compressed zone reach the extreme values, so, the condition of balance (3) is fair. It must be noted that the reason for that was that the area of the compressed fittings $\mathrm{A}_{\mathrm{s}}^{\prime}$ has been lowered with $12.32 \mathrm{sm} 2$ on $5.09 \mathrm{sm} 2$. As a result, apparently from the table -1 , the limit bending moment $\mathrm{M}_{\mathrm{ult}}$ remained almost invariable, and the specific expense of fittings has decreased by $27 \%$ - from $120.0 \mathrm{~kg} / \mathrm{m} 3$ on 88.5 $\mathrm{kg} / \mathrm{m} 3$, hat testifies to an economic benefit.

Thus, it is possible to conclude that, from the point of view of profitability, when calculating of the bent rod elements:

- it is necessary to aspire that the area of the compressed fittings was less than the area of the stretched fittings;

- control over the provision of a neutral axis by means of only a condition (1) is insufficient. It is expedient to demand also that in a limit condition of a design the compressed zone of cross section has captured the compressed fittings.

Importance of this conclusion is especially shown in problems of strengthening of the rod bent designs by method of accumulation of section.

\section{About the location of the section neutral axis when strengthening of the bent element by method of section growth}

The reinforced concrete rod bent elements strengthened by cross section growth, should be calculated as monolithic and are carried out according to instructions [2]. However researches show that except observance of the recommendations stated in [2] it is necessary to pay attention as well to some other features of calculation which outright influence profitability of strengthening. One of such feature is the additional control of neutral axis location of the strengthened design section which is carried out from a position of profitability of strengthening [3,4].

Usually when strengthening of the bent elements the neutral axis location of cross section of the strengthened construction is controlled by a condition (1). However it is not infrequent that at observance of this condition, the neutral axis appears above the compressed fittings of the strengthened element. From the point of view of reliability such circumstance is admissible. However researches show that in such cases the cumulative durability of the compressed zone materials of the strengthened construction remains with an excessive stock and, therefore, strengthening become inefficient.

We will show it on the example of 2.

\section{Example 2.}

Parameters of section of the strengthened construction are given: $b=30 \mathrm{sm}$ width; $\mathrm{h}=50 \mathrm{sm}$ height; class $\mathrm{B} 20$ concrete; the stretched $\mathrm{A}_{\mathrm{s}}=18.47 \mathrm{sm} 2$ (3Ø28) fittings: the compressed $\mathrm{A}_{\mathrm{s}}^{\prime}=6.28 \mathrm{sm} 2(2 \varnothing 20)$; A400s fittings class. It is required to strengthen a beam a 
reinforced concrete holder with finishing her bearing ability on the bending moment to $\mathrm{M}_{\mathrm{ult}}=880$ кНм.

We will consider option of strengthening at which section is increased from below on $\mathrm{y}_{1}=17.0 \mathrm{sm}$; from above on $\mathrm{y}_{2}=8.0 \mathrm{sm}$ and on each side on $\mathrm{y}_{3}=5.0 \mathrm{sm}$. Total, the sizes of section of the strengthened element make $b_{a d} \times h_{a d}=40 \times 75 \mathrm{sm}$. Concrete of the strengthening element is accepted the class B25, class A400s fittings. For further comparison reinforcing of the strengthening element it is feasible in two options:

option-1: $A_{\mathrm{s}, \mathrm{ad}}=24.55 \mathrm{sm} 2(5 \varnothing 25)$ и $\mathrm{A}_{\mathrm{s}, \mathrm{ad}}^{\prime}=18.60 \mathrm{sm} 2 \quad(2 \varnothing 20+2 \varnothing 28)$,

option-2: $\quad \mathrm{A}_{\mathrm{s}, \mathrm{ad}}=26.08 \mathrm{sm} 2(5 \varnothing 25+1 \varnothing 14)$ и $\mathrm{A}_{\mathrm{s}, \mathrm{ad}}^{\prime}=10.31 \mathrm{sm} 2 \quad(2 \varnothing 20+2 \varnothing 16)$.

Calculations are executed according to the settlement model given in [2] according to which the bearing ability of the strengthened design is determined by the bending moment by a formula:

$$
\mathrm{M}_{\mathrm{ult}}=\mathrm{R}_{\mathrm{b}, \mathrm{red}} \cdot \mathrm{b}_{\mathrm{ad}} \cdot \mathrm{x} \cdot\left(\mathrm{h}_{0, \mathrm{red}}-0.5 \mathrm{x}\right)+\mathrm{R}_{\mathrm{sc}, \mathrm{ad}} \cdot \mathrm{A}_{\mathrm{s}, \mathrm{red}}^{\prime} \cdot\left(\mathrm{h}_{0, \mathrm{red}}-\mathrm{a}_{\mathrm{red}}^{\prime}\right),
$$

ACTUAL

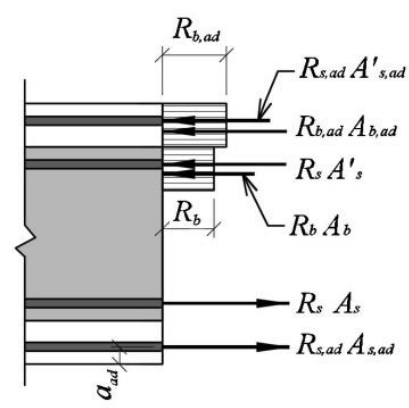

ADDUCTED

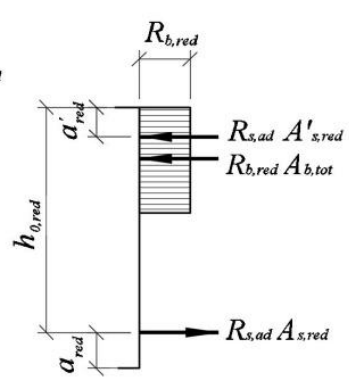

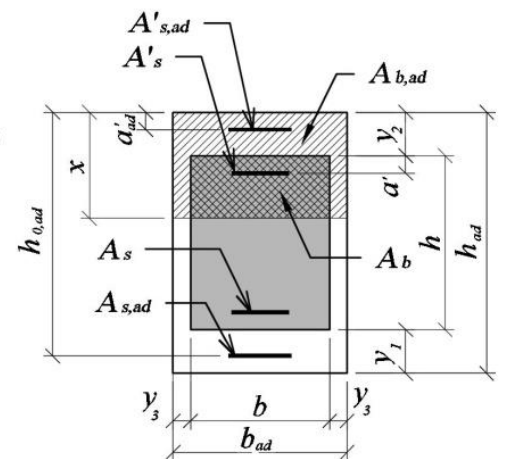

Fig. 1. The scheme of efforts in the cross section of the strengthened bent element.

where height of the compressed zone (x) is defined from a balance condition:

$$
R_{b, r e d} \cdot b_{a d} \cdot x+R_{s c, a d} \cdot A_{s, r e d}^{\prime}=R_{s, a d} \cdot A_{s, r e d}
$$

Results of calculations are given in the table-2.

From the table-2 it is visible that in both options the condition (1) is satisfied. However the neutral axis of cross section is in the first option above the compressed fittings of the strengthened element: $\mathrm{x}=11.8 \mathrm{sm}<\mathrm{a}^{\prime}+\mathrm{y}_{2}=13.0 \mathrm{sm}$ (Fig. 2). Means, in a limit condition of the strengthened tension design in materials of the compressed zone of the strengthened element don't reach the extreme values. It contradicts the value accepted in a condition of balance of efforts (9) where are accepted $\sigma_{\mathrm{b} \text {,red }}=\mathrm{R}_{\mathrm{b} \text {,red }}$ и $\sigma_{\mathrm{sc}}=\mathrm{R}_{\mathrm{sc}}$. That is the settlement intense deformed condition of the strengthened design doesn't correspond to actual state and therefore, also $\mathrm{R}_{\text {_ }}$ will be correct in a formula (9) parameters $\mathrm{R}_{\mathrm{b}, \mathrm{red}}$ и $\mathrm{R}_{\mathrm{sc}, \mathrm{ad}}$ O replace with values $\sigma_{\mathrm{b}, \mathrm{red}}$ и $\sigma_{\mathrm{sc} \text {,ad }}$. 
In the second option, apparently from the table-2, the neutral axis is below the compressed fittings of the strengthened element: $x=19.0 \mathrm{sm}<\mathrm{a}^{\prime}+\mathrm{y}_{2}=13.0 \mathrm{sm}$ (Fig. 2). Therefore, durabilities of materials of the compressed zone of section of the strengthened element in the general work of the strengthened design are used fully that is, the condition of balance (9) is fair.

Thus, the task of increase in the bearing ability of a design of the bending moment to $\mathrm{M}_{\mathrm{ult}}=880 \mathrm{kNm}$ in both options is carried out. However, apparently from comparison of results of calculation, on a specific expense of fittings the second option in relation to the first is effective for $16 \%$ thanks to a right choice of provision of a neutral axis.

One more feature of strengthening of the bent designs, noteworthy, the choice of the direction of building is. We will show it on the example reviewed above where the section of the strengthened design it was increased mainly from the stretched zone: $y_{1}=8.0 \mathrm{sm}$, $\mathrm{y}_{2}=17.0 \mathrm{sm}$. Now we will consider option at which building is made mainly from the compressed section zone: $\mathrm{y}_{1}=8.0 \mathrm{sm}, \mathrm{y}_{2}=17.0 \mathrm{sm}$ (Fig. 2). For descriptive reasons we will accept all other data accepted in the second option without change, except for the crosssectional area of the additional compressed fittings $\mathrm{A}_{\mathrm{s}, \mathrm{ad}}^{\prime}$, which is defined by calculation.
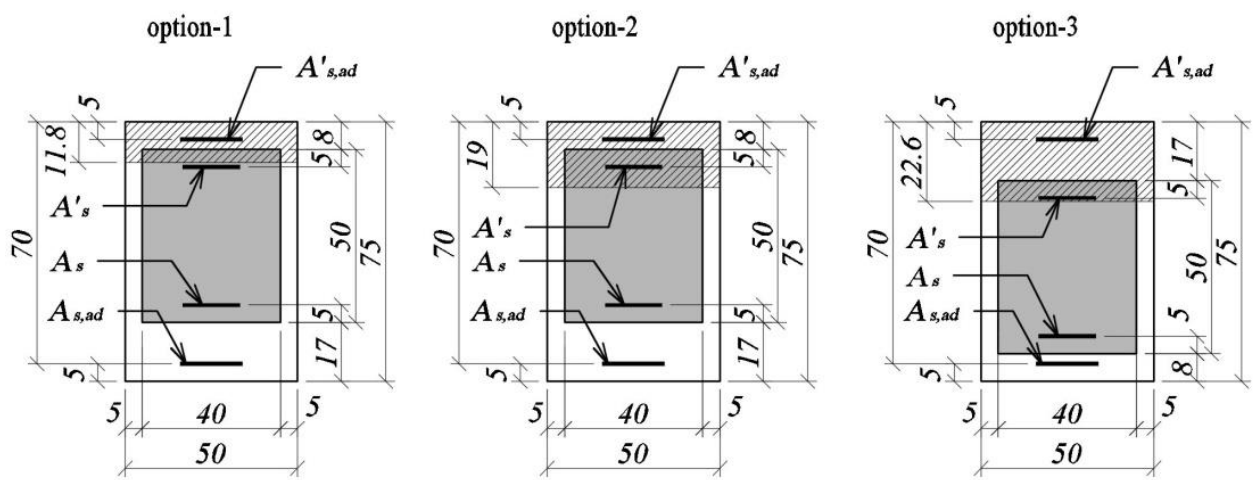

Fig. 2 Illustrations for example 2

From the table- 2 it is visible that in the third option the condition on control of provision of a neutral axis offered above is satisfied again: $x=22.6 \mathrm{sm}<\mathrm{a}^{\prime}+\mathrm{y}_{2}=22.0 \mathrm{sm}$, therefore, durabilities of materials of the compressed zone of section of the strengthened element in the general work of the strengthened design are fully used by a. Besides, from comparison with the second option it becomes obvious that the third option of strengthening is more effective as at an identical consumption of concrete the identical bearing ability is reached by a smaller expense of fittings $3.08 \mathrm{sm} 2$ against $10.31 \mathrm{sm} 2$. That is the specific consumption of fittings was cut only by one change of the direction of accumulation of section for $20 \%(152.6 \mathrm{~kg} / \mathrm{m} 3$ against $190.4 \mathrm{~kg} / \mathrm{m} 3)$.

Table 2. Accounting results

\begin{tabular}{|c|c|c|c|c|c|c|c|c|c|c|c|c|c|}
\hline \multirow{2}{*}{$\begin{array}{c}\text { Ex. } \\
2\end{array}$} & $\mathrm{R}_{\mathrm{b}, \text { red }}$ & $\mathrm{A}_{\mathrm{s}, \text { red }}^{\prime}$ & $\mathrm{A}_{\mathrm{s}, \mathrm{red}}$ & $\mathrm{a}_{\mathrm{red}}^{\prime}$ & $\mathrm{a}_{\mathrm{red}}$ & $\begin{array}{l}a^{\prime} \\
+\mathrm{y}_{2}\end{array}$ & $\mathrm{x}$ & $\xi$ & $\xi_{\mathrm{R}}$ & $\mathrm{A}_{\mathrm{s}, \mathrm{ad}}^{\prime}$ & $\mathrm{A}_{\mathrm{s}, \mathrm{ad}}$ & $\begin{array}{c}\text { Elemen } \\
\text { tary } \\
\text { dischar } \\
\text { ge of } \\
\text { fittings }\end{array}$ & $\mathrm{M}_{\mathrm{ult}}$ \\
\cline { 2 - 12 } \\
$\begin{array}{c}\mathrm{Kg} / \\
\mathrm{sm}^{2}\end{array}$ & $\mathrm{sm}^{2}$ & $\mathrm{sm}^{2}$ & $\mathrm{sm}$ & $\mathrm{sm}$ & $\mathrm{sm}$ & $\mathrm{sm}$ & & & $\mathrm{sm}^{2}$ & $\mathrm{sm}^{2}$ & $\mathrm{~kg} / \mathrm{m}^{3}$ & $\begin{array}{c}\mathrm{kN} \\
\mathrm{m}\end{array}$ \\
\hline $\begin{array}{c}\text { Opt. } \\
1\end{array}$ & 141.0 & 24.88 & 43.02 & 7.0 & 12.3 & 13.0 & 11.8 & 0.188 & 0.589 & 18.60 & 24.55 & 225.8 & $\begin{array}{c}884 \\
.0\end{array}$ \\
\hline
\end{tabular}




\begin{tabular}{|c|c|c|c|c|c|c|c|c|c|c|c|c|c|}
\hline $\begin{array}{c}\text { Opt. } \\
2\end{array}$ & 135.0 & 16.59 & 44.55 & 8.0 & 12.0 & 13.0 & 19.0 & 0.302 & 0.589 & 10.31 & 26.08 & 190.4 & $\begin{array}{c}882 \\
.0\end{array}$ \\
\hline $\begin{array}{c}\text { Opt. } \\
3\end{array}$ & 142.0 & 9.36 & 44.55 & 16.4 & 8.3 & 22.0 & 22.6 & 0.339 & 0.589 & 3.08 & 26.08 & 152.6 & $\begin{array}{c}883 \\
.0\end{array}$ \\
\hline
\end{tabular}

It is immediately apparent from the foregoing that when calculating strengthening of the bent rod elements by method of accumulation of section:

- it is expedient to demand that in a limit condition of the strengthened design the compressed zone of cross section has captured the compressed fittings of the strengthened construction.

- important economic value has a right choice of the direction of building of the strengthened construction.

\section{References}

1. Rules and regulations 63.13330.2012 Concrete and reinforced concrete structures. Basic provisions. 152 pages (2012)

2. Recommendations about design of buildings and constructions concrete structures strengthening of the reconstructed enterprises. Elevated designs and constructions (Kharkiv Promstroyniiproyekt, NIIZhB. - M.: Sroyizdat. - 1992)

3. R. G. Arutyunyan Strengthening of reinforced concrete designs by method of search optimization (Housing construction, 11, pp.12-13, 2000).

4. A.G.Tamrazyan, M.A. Orlova. Stress-strain state of concrete bending elements with cracks (Bulletin of the Tomsk state architectural and construction university, 6 (53), pp. 98-105, 2015) 